\title{
Ionic and Cellular Mechanisms Underlying the Development of Acquired Brugada Syndrome in Patients Treated with Antidepressants
}

\author{
YOSHINO MINOURA, M.D., Ph.D., JOSÉ M. DI DIEGO, M.D., HECTOR BARAJAS-MARTÍNEZ, \\ Ph.D., ANDREW C. ZYGMUNT, Ph.D., DAN HU, M.D., Ph.D., SERGE SICOURI, M.D., and \\ CHARLES ANTZELEVITCH, Ph.D., F.H.R.S. \\ Masonic Medical Research Laboratory, Utica, New York, USA
}

\section{Abstract}

\begin{abstract}
Introduction-Tricyclic antidepressants are known to induce cardiac arrhythmias at therapeutic or supratherapeutic doses. The tricyclic antidepressant, amitriptyline, is reported to induce ST segment elevation in the right precordial electrocardiogram (ECG) leads, thus unmasking Brugada syndrome $(\mathrm{BrS})$. The mechanism by which antidepressants induce the $\mathrm{BrS}$ phenotype and associated sudden death is not well established.
\end{abstract}

\begin{abstract}
Methods and Results-Action potentials (AP) were simultaneously recorded from epicardial and endocardial sites of isolated coronary-perfused canine right ventricular wedge preparations, together with a transmural pseudo-ECG. Amitriptyline alone $(0.2 \mu \mathrm{M}-1 \mathrm{mM})$ failed to induce a BrS phenotype. NS5806 $(8 \mu \mathrm{M})$, a transient outward potassium channel current $\left(\mathrm{I}_{\mathrm{to}}\right)$ agonist, was used to produce an outward shift of current mimicking a genetic predisposition to $\mathrm{BrS}$. In the presence of NS5806, a therapeutic concentration of amitriptyline $(0.2 \mu \mathrm{M})$ accentuated the epicardial AP notch leading to ST-segment elevation of the ECG. All-or-none repolarization at some epicardial sites but not others gave rise to phase-2-reentry and polymorphic ventricular tachycardia (VT) in 6 of 9 preparations. Isoproterenol $(100 \mathrm{nM})$ or quinidine $(10 \mu \mathrm{M})$ reversed the effects of amitriptyline aborting phase 2 reentry and VT (4/4). Using voltage-clamp techniques applied to isolated canine ventricular myocytes, $0.2 \mu \mathrm{M}$ amitriptyline was shown to produce usedependent inhibition of sodium channel current $\left(\mathrm{I}_{\mathrm{Na}}\right)$, without significantly affecting $\mathrm{I}_{\mathrm{to}}(\mathrm{n}=5)$.
\end{abstract}

Conclusions-Our data suggest that amitriptyline-induced inhibition of $\mathrm{I}_{\mathrm{Na}}$ unmasks the Brugada ECG phenotype and facilitates development of an arrhythmogenic substrate only in the setting of a genetic predisposition by creating repolarization heterogeneities that give rise to phase 2 reentry and VT.

\section{Keywords}

cardiac arrhythmias; sudden cardiac death; amitriptyline; Brugada syndrome; genetics

\section{Introduction}

It is well known that tricyclic antidepressants are capable of inducing cardiac arrhythmias, such as sinus tachycardia, conduction dysfunction, polymorphic ventricular tachycardia (VT), and ventricular fibrillation (VF) when taken at therapeutic or supratherapeutic doses. ${ }^{1}$

Address for correspondence: Charles Antzelevitch, Ph.D., F.A.C.C., F.A.H.A., F.H.R.S., Executive Director and Director of Research, Masonic Medical Research Laboratory, 2150 Bleecker Street, Utica, NY 13501, USA. Fax: +315-735-5648; ca@mmrl.edu.

No disclosures. 
Amitriptyline, a widely used tricyclic antidepressant, has been reported to induce an ST segment elevation in the right precordial leads (V1-V3) of the electrocardiogram (ECG) consistent with the Brugada syndrome (BrS), thus unmasking $\mathrm{BrS}^{2,3} \mathrm{BrS}$ is an inherited cardiac disorder associated with a high incidence of sudden death due to the development of life-threatening polymorphic VT and VF. Like the long-QT syndrome, BrS has an acquired component, as first suggested in 2004-2005. ${ }^{4,5}$ Although there are numerous case reports describing the induction of a BrS phenotype by antidepressant agents, the mechanism(s) responsible is poorly defined. The BrS phenotype has been reported following exposure to a wide range of antidepressant dosages, often associated with polypharmacy in the form of combinations of antidepressant drugs.

Previous studies performed in the canine ventricular wedge preparation have demonstrated that the Brugada phenotype can be induced by an outward shift in the balance of currents active at the end of phase 1 of the ventricular epicardial action potential (AP) via inhibition of sodium current $\left(\mathrm{I}_{\mathrm{Na}}\right)$, calcium current $\left(\mathrm{I}_{\mathrm{Ca}}\right)$ or augmentation of the transient outward potassium channel current $\left(\mathrm{I}_{\mathrm{to}}\right)$. Mutations leading to loss of function in $\mathrm{I}_{\mathrm{Na}}$ and $\mathrm{I}_{\mathrm{Ca}}$, as well as those giving rise to a gain of function in $\mathrm{I}_{\mathrm{to}}$, have been identified as genetic causes of BrS. $^{6-17}$ BrS has thus far been associated with mutations in 11 different genes.

The mechanism by which tricyclic antidepressants induce the Brugada ECG phenotype and the associated sudden death syndrome is not well established. ${ }^{18}$ Tricyclic antidepressants, including amitriptyline, have been reported to block $\mathrm{I}_{\mathrm{Na}}$ among other actions. ${ }^{19,20}$ The drug has also been shown to potently inhibit $\mathrm{I}_{\mathrm{to}}{ }^{21}$ Whereas inhibition of $\mathrm{I}_{\mathrm{Na}}$ can promote the $\mathrm{BrS}$ phenotype, inhibition of $I_{t o}$ will prevent its development. No studies have simultaneously evaluated the effects of therapeutic concentrations of amitriptyline on the two currents in native myocytes under identical conditions. This study tests the hypothesis that at therapeutic concentrations amitriptyline significantly blocks $\mathrm{I}_{\mathrm{Na}}$ but not $\mathrm{I}_{\mathrm{to}}$ and that block of $\mathrm{I}_{\mathrm{Na}}$ underlies the development of the electrocardiographic and arrhythmic manifestations of $\mathrm{BrS}$. In addition we examine therapeutic measures to prevent and/or suppress the tricyclic antidepressant-induced arrhythmogenesis.

\section{Methods}

These investigations conform to the Guide for Care and Use of Laboratory Animals published by the National Institutes of Health (NIH publication No. 85-23, Revised 1996) and were approved by the Institutional Animal Care and Use Committee. Detailed methods for isolation, perfusion, and recording of transmembrane activity from coronary-perfused canine right ventricular wedge preparations have been reported previously. ${ }^{22}$ Briefly, transmural wedge preparations were dissected $(1.9 \times 0.9 \times 0.9$ to $3.2 \times 1.6 \times 1.3 \mathrm{~cm})$ from the right ventricular free wall of male and female dogs weighing 20 to $35 \mathrm{~kg}$. The preparations were cannulated via a descending branch of the right coronary artery and perfused with cardioplegic solution (Tyrode's containing $12 \mathrm{mmol} / \mathrm{L} \mathrm{KCl}$ ). Unperfused tissue was carefully removed using a razor blade. The preparations were then placed in a tissue bath and arterially perfused with Tyrode's solution. The perfusate was delivered using a roller pump (Cole Parmer Instrument Co, Niles, IL, USA) at a constant flow at 8-11 mL/ $\min$. The temperature of the coronary perfusate was maintained at $37 \pm 0.5^{\circ} \mathrm{C}$.

The preparations were equilibrated in the tissue bath until electrically stable, usually 1 to 2 hours, while stimulated at a basic cycle length (BCL) of 1,000 ms using bipolar silver electrodes insulated except at the tips, applied to the endocardial surface. A transmural ECG was recorded using 2 electrodes consisting of $\mathrm{AgCl}$ half cells placed in Tyrode's solution bathing the preparation, $1.0-1.5 \mathrm{~cm}$ from the epicardial (Epi) and endocardial (Endo) 
surfaces of the preparation, along the same axis as the transmembrane recordings (Epi electrode is connected to the positive input of the ECG amplifier).

Transmembrane APs were simultaneously recorded from 2 Epi (Epi 1 [distal] and Epi 2 [proximal]; Epi1-Epi2 distance was approximately 5-10 $\mathrm{mm}$ ) and one Endo site with the use of floating microelectrodes (DC resistance $=10$ to $20 \mathrm{M} \Omega$ ) filled with $2.7 \mathrm{~mol} / \mathrm{L} \mathrm{KCl}$, each connected to a high-input impedance amplifier. Impalements were obtained from the Epi and Endo surfaces of the preparation at positions approximating the transmural axis of the ECG recording. Spike 2 for Windows (Cambridge Electronic Design, Cambridge, UK) was used to record and analyze the ECG and AP signals.

\section{Voltage-Clamp Studies Using Canine Epicardial Cells}

Single myocytes were enzymatically dissociated from the left ventricle as previously described $^{23}$ and allowed to settle and attach to the polylysine-coated floor of a $0.5 \mathrm{~mL}$ chamber mounted on a stage heater (Model PDMI-2, Harvard Apparatus, Holliston, MA, USA) on a Nikon Eclipse microscope. This chamber was perfused with Tyrode's solution at a rate of 2-3 $\mathrm{mL} / \mathrm{min}$ prior to and during gigaseal formation. The outflow of a multichannel micromanifold fast perfusion apparatus (ALA Scientific Instruments, Westbury, NY, USA) was placed within $50 \mu \mathrm{m}$ of the cell during experiments that required rapid solution changes and application of drug. Sodium and potassium currents were recorded using a Multiclamp 700B amplifier with a CV-7B headstage (Molecular Devices, Sunnyvale, CA, USA). Data will be acquired at $10 \mathrm{kHz}$ with $2 \mathrm{kHz}$ filter via a DigiData 1322A computer interface using the Molecular Devices' pClamp 9 programs.

Fast $\mathrm{I}_{\mathrm{Na}}$ and $\mathrm{I}_{\text {to }}$ were measured in low external sodium at $37^{\circ} \mathrm{C}$. Myocytes were held at -90 $\mathrm{mV}$ before eliciting a $15 \mathrm{~ms}$ pulse to $-40 \mathrm{mV}$ to record $\mathrm{I}_{\mathrm{Na}}$ immediately followed by a 185 $\mathrm{ms}$ pulse to $30 \mathrm{mV}$ to measure $\mathrm{I}_{\mathrm{to}}$. This dual pulse protocol was repeated with a diastolic interval of $70 \mathrm{~ms}$. Use-dependent block was measured during trains of 40 pulses following a rest of 30 seconds at a holding potential of $-90 \mathrm{mV}$ and expressed as either tonic block during the first pulse or steady state block during the 40th pulse. Voltage control was maintained during sodium channel activation, despite the recording temperature of $37^{\circ} \mathrm{C}$.

Voltage clamp solutions-External solutions contained (in $\mathrm{mM}$ ): $2 \mathrm{CaCl}_{2}, 10$ glucose, 1 $\mathrm{MgCl}_{2}, 4 \mathrm{KCl}, 40 \mathrm{NaCl}, 105 \mathrm{~N}$-methyl-D-glucamine, 10 HEPES, $\mathrm{pH}$ adjusted to 7.4 with $\mathrm{HCl}$. $\mathrm{CdCl}_{2}(300 \mu \mathrm{M})$ was added to the external solution to block $\mathrm{I}_{\mathrm{Ca}}$ and further reduce $\mathrm{I}_{\mathrm{Na}}$. The pipette solution contained (in $\mathrm{mM}$ ): $1 \mathrm{MgCl}_{2}, 10 \mathrm{NaCl}, 10 \mathrm{KCl}, 125 \mathrm{~K}$-aspartate, 10 HEPES, 5 EGTA, $5 \mathrm{MgATP}$, and $\mathrm{pH}$ adjusted to 7.1 with $\mathrm{KOH}$. When checking for voltage control, $\mathrm{KCl}$ was eliminated from the external solution and cesium was substituted for potassium to produce potassium-free external and pipette solutions.

\section{Transfection of the TSA201 Cell Line and Electrophysiology}

Sodium channels were expressed in a human embryonic kidney cell line, TSA201, as previously described. Briefly, transient transfection was carried out with Fugene using a 1:1 molar ratio of SCN5A wild-type (WT) and SCN1B (WT) cDNA plasmid. In addition, CD8 cDNA in a 2.4:1 molar ratio was cotransfected as a reporter gene to visually identify transfected cells using Dynabeads (M-450 CD8, Invitrogen Corp., Carlsbad, CA, USA). Channel characteristic were studied 72 hours after transfection and placed in a chamber for electro-physiological study (EPS; Medical Systems, Greenvale, NY, USA).

Macroscopic whole-cell $\mathrm{I}_{\mathrm{Na}}$ was recorded at room temperature $\left(22^{\circ} \mathrm{C}\right)$ using an Axopatch 200B amplifier (Molecular Devices). Perfusion bath solution containing (in mmol/L) 140 $\mathrm{NaCl}, 5 \mathrm{KCl}, 1.8 \mathrm{CaCl} 2,1 \mathrm{MgCl}_{2}, 2.8 \mathrm{Na}$ acetate, 10 HEPES, and 10 glucose $(\mathrm{pH} 7.3$ with 
$\mathrm{NaOH})$. Tetraethylammonium chloride ( $5 \mathrm{mmol} / \mathrm{L}$ ) was added to the buffer to block TEAsensitive native currents. Patch clamp pipettes were pulled (1 and $2.5 \mathrm{M} \Omega$ ) from borosilicate glass (7052; Model PP-89; Narashige, Tokyo, Japan) and filled with a solution containing (in mmol/L) $5 \mathrm{NaCl}, 5 \mathrm{KCl}, 130 \mathrm{CsF}, 1.0 \mathrm{MgCl}_{2}, 5 \mathrm{EGTA}$, and $10 \mathrm{HEPES}$ (pH 7.2 with $\mathrm{CsOH}$ ). Steady-state availability of the sodium channel was fitted to a Boltzmann equation. Data acquisition and analysis were performed using pCLAMP programs V9.2 (Axon Instruments, Union City, CA, USA) and ORIGIN 6.1 (Microcal Software, Northampton, MA, USA).

Drugs-NS5806 was a kind gift of Neurosearch A/S, Ballerup, Denmark. Isoproterenol and quinidine sulfate was purchased from Sigma-Aldrich Corp., St. Louis, MO, USA.

Statistics-Statistical analysis was performed using Student's $t$-test for paired data or oneway repeated measures ANOVA in combination with a Dunnet or Bonferroni test, as appropriate. All data are reported as mean \pm SD.

The authors had full access to the data and take responsibility for its integrity. All authors have read and agree to the manuscript as written.

\section{Results}

We have previously demonstrated that an outward shift in the balance of currents active during the early phases of the right ventricular Epi AP either via inhibition of inward depolarizing current or augmentation of outward repolarizing current can recapitulate the BrS phenotype in the canine ventricular wedge preparation. ${ }^{22,24}$ In this study, we considered both possibilities as a cause of amitriptyline-induced $\mathrm{BrS}$.

\section{Amitriptyline Induction of Phase 2 Reentry and VT/VF in the Coronary-Perfused Right Ventricular (RV) Wedge Model}

At first, we assessed whether amitriptyline alone could recapitulate the ECG and arrhythmic manifestations of BrS. Figure 1A shows tracings recorded from coronary-perfused wedge preparations in control and after amitriptyline. Action potential duration (APD) measured at 90\% repolarization $\left(\mathrm{APD}_{90}\right)$ and $\mathrm{QRS}$ duration were unchanged following exposure to amitriptyline $(0.2 \mu \mathrm{M})$ (Table 1, panel A). The amplitude and magnitude of phases 1 and 2 of the AP were measured. The epicardial action potential notch (APN) magnitude (NM); [100 - (100 $\times$ phase 1 amplitude/phase 2 amplitude) $]$ phase 0 to phase 2 interval ( $\mathrm{Ph} 0-\mathrm{Ph} 2)$; [time between the first 2 peaks of the derivative of the AP] as well as the notch magnitude index (NMI); [NM $\times(\mathrm{Ph} 0-\mathrm{Ph} 2$ interval)] that approximates the area of the notch were measured before and after amitriptyline. ${ }^{22}$ Amitripty-line $(0.2 \mu \mathrm{M})$ alone did not increase APN, NM, or NMI or induce any arrhythmia $(n=4)$ (Table 1, panel B, Fig. 1C). In another series of experiments, we sought to assess whether high (toxic) concentrations of amitriptyline $(0.5 \mu \mathrm{M}-1 \mathrm{mM})(\mathrm{n}=4)$ could cause arrhythmic manifestations. We failed to observe a BrS phenotype or the development of arrhythmias at concentrations as high as 1 $\mathrm{mM}$.

An outward shift of current active during the early phases of the AP is known to facilitate the development of the $\mathrm{BrS}$ phenotype and is the basis for the genetic predisposition to $\mathrm{BrS}$. We sought to mimic such a genetic predisposition by using NS5806, to augment $\mathrm{I}_{\mathrm{to}}$. An augmented $\mathrm{I}_{\text {to }}$ is known to underlie the $\mathrm{BrS6}$ and $\mathrm{BrS} 10$ forms of $\mathrm{BrS}^{12,16}$ and higher levels of $\mathrm{I}_{\text {to }}$ are thought to underlie the predominance of the BrS phenotype in males. ${ }^{25,26}$ Figure 1B shows traces recorded from coronary-perfused wedge preparations in control, after $8 \mu \mathrm{M}$ NS5806 and $0.2 \mu \mathrm{M}$ amitriptyline. NS5806 $(8 \mu \mathrm{M})$ significantly increased the epicardial all parameters associated with the APN and accentuated the apparance of the J wave (Table 1, 
panel B). Amitriptyline $(0.2 \mu \mathrm{M})$ produced a further significant increase of AP notch parameters as well as the $\mathrm{J}$ wave $(\mathrm{n}=9)$ (Table 1, panel B).

As illustrated in Figure 2, amitriptyline $(0.2 \mu \mathrm{M})$ caused loss of the AP dome in Epi2 but not Epi1. Phase 2 reentry developed as the Epi AP dome propagated from sites at which it was maintained to sites at which it was lost. This mechanism generated closely coupled extrasystoles in 8 of 9 preparations as well as polymorphic VT/VF in 6 of 9 wedge preparations. The failure to induce polymorphic VT in $3 / 9$ preparation is likely due to the presence of a limited path length relative to the reentrant wavelength within these RV wedge preparations. VT/VF was not observed nor could it be induced following washout of amitriptyline in the continued presence of NS5806. Washout of amitriptyline led to restoration of the AP dome. Following washout, AP notch was reduced (Table 1, panel C). Neither phase 2 reentry nor VT/VF could be induced with programmed stimulation after washout of amitriptyline.

\section{Isoproterenol (ISO) and Quinidine Suppress or Inhibit Induction of Phase 2 Reentry and VT/VF by Amitriptyline}

In another series of experiments, we tested the hypothesis that rebalancing of the currents active during the early phases of the epicardial AP could reverse the effects of amitripty-line and prevent the ECG and arrhythmic manifestations of $\mathrm{BrS}$. We used isoproterenol (ISO) to augment $\mathrm{I}_{\mathrm{Ca}}$ and quini-dine to reduce $\mathrm{I}_{\mathrm{to}}$. Figure $3 \mathrm{~A}$ shows tracings recorded from coronaryperfused wedge preparations under control conditions, after the addition of $8 \mu \mathrm{M}$ NS5806 alone, NS5806 plus amitriptyline, after further addition of ISO, washout of ISO, and finally after further addition of quinidine (Fig. 3A). ISO and quinidine significantly reduced all epicardial action potential notch parameters (Fig. 3B-D). In the example illustrated in Figure 4, amitriptyline $(0.2 \mu \mathrm{M})$ and NS5806 $(8 \mu \mathrm{M})$ induced marked accentuation of the epicardial AP notch and $\mathrm{J}$ wave. The addition of either $100 \mathrm{nM}$ ISO or $10 \mu \mathrm{M}$ quinidine to the coronary perfusate greatly reduced the epicardial notch as well as the J wave. All AP notch parameters were significantly reduced after ISO or quinidine (Table 1, panel C).

We examined the effectiveness of ISO and quinidine to suppress the induction of VT/VF by amitriptyline. Once phase 2 reentry and VT/VF were induced by amitriptyline, addition of ISO $(100 \mathrm{nM})$ terminated the arrhythmia, reversed the repolarization heterogeneities and normalized the ECG in 4 of 4 preparations (Fig. 4). Quinidine $(10 \mu \mathrm{M})$ terminated the arrhythmia, reversed the repolarization heterogeneities and normalized the ECG in 4 of 4 preparations (Fig. 4).

\section{The Potency of Amitriptyline to Inhibit $I_{\mathrm{Na}}$ and $I_{\text {to }}$}

Amitriptyline has been reported to inhibit both $\mathrm{I}_{\mathrm{Na}}$ and $\mathrm{I}_{\mathrm{to}}$. In another series of experiments we sought to determine the extent to which $0.2 \mu \mathrm{M}$ amitriptyline blocks the 2 currents, since this was the concentration of the drug that was found to be effective in inducing the $\mathrm{BrS}$ phenotype. We examined the effect of 0.2 and $0.5 \mu \mathrm{M}$ amitriptyline to inhibit $\mathrm{I}_{\mathrm{Na}}$ and $\mathrm{I}_{\mathrm{to}}$ in canine ventricular epicardial myocytes using patch clamp techniques. Voltage clamp protocols were run in control solution and repeated in the presence of drug. Use-dependent block (UDB) was measured during trains of 40 pulses following a rest of 30 seconds at a holding potential (HP) of $-90 \mathrm{mV}$ and expressed as either tonic block during the first pulse or steady state block during the 40th pulse. Figure 5A-C shows steady-state block of $\mathrm{I}_{\mathrm{Na}}$ and $\mathrm{I}_{\mathrm{to}}$. Amitriptyline $(0.2 \mu \mathrm{M})$ inhibited $\mathrm{I}_{\mathrm{Na}}$ in a use- and concentration-dependent manner without similarly affecting $I_{\text {to }}(n=5)$. Steady state block of sodium channels was $36.9 \pm$ $0.03 \%$ in the presence of $0.2 \mu \mathrm{M}$ amitriptyline, and $62.9 \pm 0.03 \%$ with $0.5 \mu \mathrm{M}$ of drug. Appropriate time controls showed that potassium current was unaffected by amitriptyline. 
Because blockade of ion channels by antiarrhythmic agents is known to be temperature sensitive, ${ }^{27}$ we sought conditions that would permit recording $\mathrm{I}_{\mathrm{Na}}$ at $37{ }^{\circ} \mathrm{C}$. The loss of voltage control while recording $\mathrm{I}_{\mathrm{Na}}$ at physiological temperature is always a concern. Figure 5D shows the smooth bell-shaped current-voltage curve generated at physiological temperature when external sodium was reduced to $40 \mathrm{mM} \mathrm{Na}$ in the presence of $0.3 \mathrm{mM}$ $\mathrm{CdCl}_{2}$ and steps were taken from a HP of $-90 \mathrm{mV}$. The lack of an abrupt jump of inward current near the sodium channel threshold is taken as a measure of adequate voltage control. It follows that the drug-induced reduction of $\mathrm{I}_{\mathrm{Na}}$ shown in Figure 5D was not a response caused by changes in voltage control while activating sodium channels.

We also examined the voltage-dependent effect of amitriptyline in TSA201 cells expressing the $\alpha$ and $\beta 1$ subunits. Figure 6 shows the effect of $0.2 \mu \mathrm{M}$ amitriptyline on UDB of $\mathrm{I}_{\mathrm{Na}}$, the current-voltage relationship and steady-state inactivation. UDB was examined at $0.5 \mathrm{~Hz}$ with $20 \mathrm{~ms}$-long test pulse to $40 \mathrm{mV}$ from a $\mathrm{HP}$ of $-110 \mathrm{mV}$ before and after amitriptyline. In the presence of $0.2 \mu \mathrm{M}$ amitriptyline, we observed UDB at $\mathrm{HP}-110 \mathrm{mV}$ (Fig. 6A and B). $\mathrm{I}_{\mathrm{Na}}$ was elicited with $200-\mathrm{ms}$ pulses for the I-V relationship. Amitriptyline caused $55.4 \pm 1.6 \%$ reduction of the maximum current at $-20 \mathrm{mV}(\mathrm{P}<0.01, \mathrm{n}=5$ ) (Fig. 6C). Steady-state inactivation curve was obtained using a $500 \mathrm{~ms}$ prepulse to different voltages followed by a step to $-20 \mathrm{mV}$. Amitriptyline shifted half-inactivation potential (Hinf50) from $-91.6 \pm 0.5$ to $-98.3 \pm 0.3(\mathrm{P}<0.01, \mathrm{n}=5)$ (Fig. 6D).

\section{Discussion}

This study demonstrates for the first time the effect of the tricyclic antidepressant amitriptyline to induce the electrocardiographic and arrhythmic manifestations of $\mathrm{BrS}$ in an experimental model consisting of a coronary-perfused canine RV wedge preparation. Our results suggest that amitriptyline at a concentration of $0.2 \mu \mathrm{M}$ produces relatively potent inhibition of $\mathrm{I}_{\mathrm{Na}}$ and little inhibition of $\mathrm{I}_{\mathrm{to}}$ such that in the setting of a genetic predisposition, created by an outward shift of net repolarizing current, it can induce a Brugada phenotype.

Under these conditions amitriptyline can importantly accentuate the RV AP notch and J wave, leading to heterogeneous loss of the AP dome and the development of phase 2 reentry, which is responsible for generating a closely coupled extrasystole, capable of precipitating polymorphic VT.

Tricyclic antidepressants, even when administered at therapeutic doses, are known to induce cardiac arrhythmias. ${ }^{1,3}$ In a study of 98 patients experiencing an overdose of tricyclic antidepressants, Goldgran-Toledano et al. ${ }^{18}$ reported that overall mortality among all patients was 3\%, but among patients who displayed a Brugada phenotype it was $6.7 \%$. Rouleau et al. ${ }^{3}$ reported 3 cases of psychotropic drug-induced Brugada ECG, occurring during coadministration of amitriptyline and other antipsychotic drugs. A number of similar cases of acquired BrS have been reported following tricyclic antidepressant overdose, 2,28,29 but the role of individual tricyclic antidepressants, including amitriptyline, was unclear because of the polypharmacy associated with these cases.,3 (see Ref.1 for review). The mechanism by which these tricyclic antidepressant induce the Brugada ECG phenotype was not well defined. When the therapeutic doses of antidepressants are associated with arrhythmogenesis, it is possible that a genetic predisposition exists, although this hypothesis is as yet unexplored.

We examined the effect of amitriptyline to inhibit both inward and outward currents in canine ventricular myocytes. While amitriptyline, like most antidepressants, is known to potently block $\mathrm{I}_{\mathrm{Na}}, 19,30$ its actions on the other currents contributing to the early phases of the AP are not well defined. Barber et al. reported that amitriptyline $(0.4 \mu \mathrm{M})$ blocks $\mathrm{I}_{\mathrm{Na}}$ by up to $80 \%$ in a use-dependent manner using rabbit atrial and ventricular myocytes. ${ }^{19}$ Casis 
et al. reported that amitriptyline blocks $\mathrm{I}_{\text {to }}$ with an $\mathrm{IC}_{50}$ of $6.98 \mu \mathrm{M}$ in isolated rat ventricular cardiomyocytes. ${ }^{21} \mathrm{Few}$ data are available relative to the effect of amitriptyline on L-type calcium channel current $\left(\mathrm{I}_{\mathrm{Ca}}\right)$. Amitriptyline has been reported to block $\mathrm{I}_{\mathrm{Ca}}$ in rat ventricular myocytes with a half maximal inhibitory concentration $\left(\mathrm{IC}_{50}\right)$ of $3.75 \mu \mathrm{M} .{ }^{31}$ The multi-ion channel inhibitory actions of amitriptyline, particularly its simultaneous block of inward $\left(\mathrm{I}_{\mathrm{Na}}\right.$ and $\left.\mathrm{I}_{\mathrm{Ca}}\right)$ and outward $\left(\mathrm{I}_{\mathrm{to}}\right)$ currents, account for the fact that the drug alone fails to induce a BrS phenotype. An outward shift of current active during the early phases of the epicardial action potential, whether due to an increase in $\mathrm{I}_{\mathrm{to}}$ or a decrease in $\mathrm{I}_{\mathrm{Na}}$ or $\mathrm{I}_{\mathrm{Ca}}$, is known to predispose to the development of the BrS phenotype. This facilitation is often the result of a genetic background causing a loss of function of inward currents or a gain of function of outward currents. In this study, we mimic such a genetic background with the use of an $\mathrm{I}_{\text {to }}$ agonist and demonstrate that only in this setting can amitriptyline induce the electrocardiographic and arrhythmic manifestations of BrS. Thus, our data suggest that when phase 1 repolarization reserve is enhanced by either a genetic variation or another drug can amitriptyline readily induce a BrS phenotype, when used at a concentration at which $\mathrm{I}_{\mathrm{Na}}$, but not $\mathrm{I}_{\mathrm{to}}$, is significantly inhibited. It is noteworthy that previous demonstrations of amitriptyline-induced inhibition of $\mathrm{I}_{\mathrm{to}}$ were at concentrations more than and order of magnitude greater than used in our study and were done in a different species (rat vs (anine). ${ }^{21}$

No study to date has examined the effects of amitriptyline on both inward and outward currents in the same cell type. The outward shift in the balance of currents needed to induce the BrS phenotype can result from augmentation of $\mathrm{I}_{\mathrm{to}}$, or suppression of $\mathrm{I}_{\mathrm{Na}}$. Suppression of $\mathrm{I}_{\mathrm{Na}}$, causing an outward shift in the balance currents at the end of phase 1 can be counterbalanced by amitriptyline's action to also inhibit $\mathrm{I}_{\mathrm{to}}$. As demonstrated in this study, amitriptyline produces UDB of $\mathrm{I}_{\mathrm{Na}}$ in canine ventricular cells at concentrations approximating the therapeutic range of the drug $(0.3-0.8 \mu \mathrm{M})^{20}$ without inhibition of $\mathrm{I}_{\text {to }}$ at these concentrations. These effects and conditions underlie the ability of the drug to cause an outward shift in the balance of currents at the end of phase 1 of the RV Epi AP. The resultant heterogeneous loss of the Epi AP dome leads to the electrocardiographic and arrhythmic manifestations of BrS.

Amitriptyline was also shown to inhibit $\mathrm{I}_{\mathrm{Na}}$ in a use-dependent manner in TSA201 cells (a modified human embryonic kidney cell line) expressing the $a$ and $\beta 1$ subunit of the cardiac sodium channel consistent with previous reports in heterologous expression systems. This experimental series also demonstrated that part of the effect of amitriptyline to suppress $\mathrm{I}_{\mathrm{Na}}$ is due to its action to produce a negative shift of the voltage dependence of inactivation (Fig. $5 \mathrm{D})$.

Amitriptyline generally induced phase 2 reentry and polymorphic VT at relatively slow rates (basic cycle length $(\mathrm{BCL})=2,000 \mathrm{~ms}$ ). This observation is consistent with the greater availability of $I_{t o}$ at slower rates owing to its relatively long reactivation time constant. At these rates, however, the action of the drug to inhibit $\mathrm{I}_{\mathrm{Na}}$ is reduced such that arrhythmogenesis was only observed in preparations pretreated with the $\mathrm{I}_{\text {to }}$ agonist NS5806. This finding is consistent with the fact that $\mathrm{BrS}$ is more readily induced in $\mathrm{RV}$ wedge preparations isolated from male dogs, who exhibit higher levels of $\mathrm{I}_{\mathrm{to}}{ }^{25}$ This observation is also consistent with the finding that $\mathrm{BrS}$, both congenital and acquired, is more prevalent in males than in females. ${ }^{26,32}$ The induction of BrS in preparations sensitized with NS5806 may also serve as a surrogate for the development of $\mathrm{BrS}$ in individuals exposed to therapeutic or surpratherapeutic levels of amitriptyline who are genetically predisposed.

BrS has been associated with mutations in 11 different genes. Over 300 mutations in SCN5A $\left(\mathrm{Na}_{\mathrm{v}} 1.5, \mathrm{BrS} 1\right)$ have been reported in $11-28 \%$ of BrS probands. ${ }^{6,7,33}$ Mutations in 
CACNA1C $\left(\mathrm{Ca}_{\mathrm{v}} 1.2, \mathrm{BrS3}\right), \mathrm{CACNB} 2 \mathrm{~b}\left(\mathrm{Ca}_{\mathrm{v}} \beta 2 \mathrm{~b}, \mathrm{BrS} 4\right)$, and CACNA2D1 $\left(\mathrm{Ca}_{\mathrm{v}} \mathrm{a} 2 \delta, \mathrm{BrS} 9\right)$ are found in approximately $13 \%$ of probands. ${ }^{9}, 14$ Mutations in glycerol-3-phophate dehydrogenase 1-like enzyme gene (GPD1L, BrS2), SCN1B ( $\beta 1$-subunit of Na channel, BrS5), KCNE3 (MiRP2; BrS6), SCN3B ( 33 -subunit of Na channel, BrS7), KCNJ8 (BrS8), and $K C N D 3(\mathrm{BrS10})$ are more rare. ${ }^{10-12,15,16,34}$ These genetic defects cause a loss of function of $\mathrm{I}_{\mathrm{Na}}$ or $\mathrm{I}_{\mathrm{Ca}}$, or a gain of function of $\mathrm{I}_{\mathrm{to}}$. These and other genetic variants may give rise to subclinical forms of $\mathrm{BrS}$, that can predispose to acquired forms of $\mathrm{BrS}$ developing following administration of antidepressants such as amitriptyline and pharmacological agents with similar actions. Amitriptyline also has been reported to cause QT prolongation in $\mathrm{ECG}^{35}$ due to block the rapid delayed rectifier potassium current (IKr). ${ }^{36}$ Recently it has been reported that SCN5A mutation are not directly causal for BrS phenotype. ${ }^{37}$ We need to consider other genetic effects because the balance of all currents active during the early phases of the AP recapitulate the BrS phenotype. Each genetic background of the patient can lead different phenotype by amitriptyline.

Traditionally, pharmacologic therapy for BrS has been aimed at rebalancing the currents active during the early phases of the Epi AP, either by increasing $\mathrm{I}_{\mathrm{Ca}}$ or reducing $\mathrm{I}_{\mathrm{to}}$. We examined the effectiveness of ISO and quinidine in our amitriptyline-induced $\mathrm{BrS}$ model. Both agents prevented the development of the substrate or reversed the arrhythmogenic effects by amitriptyline by restoring the epicardial AP dome, thus acting to restore homogeneity of repolarization. ISO via its actions to stimulate cyclic AMP augments $\mathrm{I}_{\mathrm{Ca}}$ and quinidine via its actions to inhibit $\mathrm{I}_{\mathrm{to}}$ produce an inward shift of the balance of currents active during the early phases of the epicardial AP. These findings suggest that these two agents may be effective in the treatment of amitriptyline-induced arrhythmias as it has been in the treatment of arrhythmias associated with congenital BrS. ${ }^{24,38,39}$ Quinidine, in addition to its actions to block $\mathrm{I}_{\mathrm{to}}$, also blocks $\mathrm{I}_{\mathrm{Na}}, \mathrm{I}_{\mathrm{Kr}}$ and $\mathrm{I}_{\mathrm{Ks}}$ at therapeutic plasma levels. These multi-ion channel inhibitory actions notwithstanding, its utility to mitigate the arrhythmogenic substrate associated with the BrS phenotype is well established. ${ }^{39}$

\section{Study Limitations}

Extrapolation of the data from these in vitro models to the clinic must be done with great caution since a number of assumptions must be carefully considered. Among these is the supposition that pretreatment with NS5806 is a reasonable surrogate for elevated levels of $\mathrm{I}_{\text {to }}$ that may be encountered physiologically or pathophysiologically in association with a genetic predisposition to BrS. The shift in steady-state inactivation following amitriptyline may be underestimated in view of the relatively slow dissociation of the drug from the sodium channel.

In order to evaluate the actions of amitriptyline to inhibit $\mathrm{I}_{\mathrm{Na}}$ and $\mathrm{I}_{\mathrm{to}}$ under circumstances approximating physiologic conditions, we recorded these currents under identical conditions at $37^{\circ} \mathrm{C}$. Voltage control is an obvious concern under these conditions and we took precautions to ensure such control, including use of low extracellular $\mathrm{Na}$ and use of $\mathrm{CdCl}_{2}$ to limit $\mathrm{I}_{\mathrm{Na}}$ intensity. As illustrated in Figure 5D, the lack of an abrupt jump of inward current near the sodium channel threshold and a smooth bell-shaped current-voltage relation was taken as a measure of adequate voltage control.

\section{Acknowledgments}

We gratefully acknowledge the technical assistance of Judy Hefferon and Robert Goodrow.

This study was supported by HL47678 from NHLBI to Dr. Antzelevitch, a fellowship from the Japanese Heart Rhythm Society to Dr. Minoura, and the Masons of New York State and Florida. 


\section{References}

1. Sicouri S, Antzelevitch C. Sudden cardiac death secondary to antidepressant and antipsychotic drugs. Expert Opin Drug Saf. 2008; 7:181-194. [PubMed: 18324881]

2. Bolognesi R, Tsialtas D, Vasini P, Conti M, Manca C. Abnormal ventricular repolarization mimicking myocardial infarction after heterocyclic antidepressant overdose. Am J Cardiol. 1997; 79:242-245. [PubMed: 9193039]

3. Rouleau F, Asfar P, Boulet S, Dube L, Dupuis JM, Alquier P, Victor J. Transient ST segment elevation in right precordial leads induced by psychotropic drugs: Relationship to the Brugada syndrome. J Cardiovasc Electrophysiol. 2001; 12:61-65. [PubMed: 11204086]

4. Antzelevitch C, Brugada P, Borggrefe M, Brugada J, Brugada R, Corrado D, Gussak I, LeMarec H, Nademanee K, Perez Riera AR, Shimizu W, Schulze-Bahr E, Tan H, Wilde A. Brugada syndrome: Report of the second consensus conference. Endorsed by the Heart Rhythm Society and the European Heart Rhythm Association. Circulation. 2005; 111:659-670. [PubMed: 15655131]

5. Shimizu, W. Acquired forms of Brugada syndrome. In: Antzelevitch, C., editor. The Brugada Syndrome: From Bench to Bedside. Blackwell Futura; Oxford, UK: 2004. p. 166-177.

6. Chen Q, Kirsch GE, Zhang D, Brugada R, Brugada J, Brugada P, Potenza D, Moya A, Borggrefe M, Breithardt G, Ortiz-Lopez R, Wang Z, Antzelevitch C, O'Brien RE, Schultze-Bahr E, Keating MT, Towbin JA, Wang Q. Genetic basis and molecular mechanisms for idiopathic ventricular fibrillation. Nature. 1998; 392:293-296. [PubMed: 9521325]

7. Schulze-Bahr E, Eckardt L, Breithardt G, Seidl K, Wichter T, Wolpert C, Borggrefe M, Haverkamp W. Sodium channel gene ( $S C N 5 A$ ) mutations in 44 index patients with Brugada syndrome: Different incidences in familial and sporadic disease. Hum Mutat. 2003; 21:651-652. [PubMed: 14961552]

8. Kapplinger JD, Tester DJ, Alders M, Benito B, Berthet M, Brugada J, Brugada P, Fressart V, Guerchicoff A, Harris-Kerr C, Kamakura S, Kyndt F, Koopmann TT, Miyamoto M, Pfeiffer R, Pollevick GD, Probst V, Zumhagen S, Vatta M, Towbin JA, Shimizu W, Schulze-Bahr E, Antzelevitch C, Salisbury BA, Guicheney P, Wilde AAM, Brugada R, Schott JJ, Ackerman MJ. An international compendium of mutations in the SCN5A encoded cardiac sodium channel in patients referred for Brugada syndrome genetic testing. Heart Rhythm. 2010; 7:33-46. [PubMed: 20129283]

9. Antzelevitch C, Pollevick GD, Cordeiro JM, Casis O, Sanguinetti MC, Aizawa Y, Guerchicoff A, Pfeiffer R, Oliva A, Wollnik B, Gelber P, Bonaros EP Jr, Burashnikov E, Wu Y, Sargent JD, Schickel S, Oberheiden R, Bhatia A, Hsu LF, Haissaguerre M, Schimpf R, Borggrefe M, Wolpert C. Loss-of-function mutations in the cardiac calcium channel underlie a new clinical entity characterized by ST-segment elevation, short QT intervals, and sudden cardiac death. Circulation. 2007; 115:442-449. [PubMed: 17224476]

10. London B, Michalec M, Mehdi H, Zhu X, Kerchner L, Sanyal S, Viswanathan PC, Pfahnl AE, Shang LL, Madhusudanan M, Baty CJ, Lagana S, Aleong R, Gutmann R, Ackerman MJ, McNamara DM, Weiss R, Dudley SC Jr. Mutation in glycerol-3-phosphate dehydrogenase 1 like gene (GPD1-L) decreases cardiac $\mathrm{Na}^{+}$current and causes inherited arrhythmias. Circulation. 2007; 116:2260-2268. [PubMed: 17967977]

11. Watanabe H, Koopmann TT, Le Scouarnec S, Yang T, Ingram CR, Schott JJ, Demolombe S, Probst V, Anselme F, Escande D, Wiesfeld AC, Pfeufer A, Kaab S, Wichmann HE, Hasdemir C, Aizawa Y, Wilde AA, Roden DM, Bezzina CR. Sodium channel b1 subunit mutations associated with Brugada syndrome and cardiac conduction disease in humans. J Clin Invest. 2008; 118:22602268. [PubMed: 18464934]

12. Delpón E, Cordeiro JM, Núñez L, Thomsen PEB, Guerchicoff A, Pollevick GD, Wu Y, Kanters JK, Larsen CT, Burashnikov A, Christiansen M, Antzelevitch C. Functional effects of KCNE3 mutation and its role in the development of Brugada syndrome. Circ Arrhythm Electrophysiol. 2008; 1:209-218. [PubMed: 19122847]

13. Hu D, Barajas-Martinez H, Burashnikov E, Springer M, Wu Y, Varro A, Pfeiffer R, Koopmann TT, Cordeiro JM, Guerchicoff A, Pollevick GD, Antzelevitch C. A mutation in the beta 3 subunit of the cardiac sodium channel associated with Brugada ECG phenotype. Circ Cardiovasc Genet. 2009; 2:270-278. [PubMed: 20031595] 
14. Burashnikov E, Pfeiffer R, Barajas-Martinez H, Delpon E, Hu D, Desai M, Borggrefe M, Haissaguerre M, Kanter R, Pollevick GD, Guerchicoff A, Laino R, Marieb M, Nademanee K, Nam GB, Robles R, Schimpf R, Stapleton DH, Viskin S, Winters S, Wolpert C, Zimmern S, Veltmann C, Antzelevitch C. Mutations in the cardiac L-type calcium channel associated J wave sydnrome and sudden cardiac death. Heart Rhythm. 2010; 7:1872-1882. [PubMed: 20817017]

15. Medeiros-Domingo A, Tan BH, Crotti L, Tester DJ, Eckhardt L, Cuoretti A, Kroboth SL, Song C, Zhou Q, Kopp D, Schwartz PJ, Makielski JC, Ackerman MJ. Gain-of-function mutation S422L in the KCNJ8-encoded cardiac K(ATP) channel Kir6.1 as a pathogenic substrate for J-wave syndromes. Heart Rhythm. 2010; 7:1466-1471. [PubMed: 20558321]

16. Giudicessi JR, Ye D, Tester DJ, Crotti L, Mugione A, Nesterenko VV, Albertson RM, Antzelevitch C, Schwartz PJ, Ackerman MJ. Transient outward current (Ito) gain-of-function mutations in the KCND3-encoded Kv4.3 potassium channel and Brugada syndrome. Heart Rhythm. 2011; 8:1024-1032. [PubMed: 21349352]

17. Kattygnarath D, Maugenre S, Neyroud N, Balse E, Ichai C, Denjoy I, Dilanian G, Martins RP, Fressart V, Berthet M, Schott JJ, Leenhardt A, Probst V, Le MH, Hainque B, Coulombe A, Hatem SN, Guicheney P. MOG1: A new susceptibility gene for Brugada syndrome. Circ Cardiovasc Genet. 2011; 4:261-268. [PubMed: 21447824]

18. Goldgran-Toledano D, Sideris G, Kevorkian JP. Overdose of cyclic antidepressants and the Brugada syndrome. N Engl J Med. 2002; 346:1591-1592. [PubMed: 12015405]

19. Barber MJ, Starmer CF, Grant AO. Blockade of cardiac sodium channels by amitriptyline and diphenylhydantoin. Evidence for two use-dependent binding sites. Circ Res. 1991; 69:677-696. [PubMed: 1651817]

20. Nau C, Seaver M, Wang SY, Wang GK. Block of human heart hH1 sodium channels by amitriptyline. J Pharmacol Exp Ther. 2000; 292:1015-1023. [PubMed: 10688618]

21. Casis O, Sanchez-Chapula JA. Mechanism of block of cardiac transient outward $\mathrm{K}+$ current $I_{\text {to }}$ by antidepressant drugs. J Cardiovasc Pharmacol. 1998; 32:527-534. [PubMed: 9781920]

22. Fish JM, Welchons DR, Kim YS, Lee SH, Ho WK, Antzelevitch C. Dimethyl lithospermate B, an extract of danshen, suppresses arrhythmogenesis associated with the Brugada syndrome. Circulation. 2006; 113:1393-1400. [PubMed: 16534004]

23. Calloe K, Cordeiro JM, Di Diego JM, Hansen RS, Grunnet M, Olesen SP, Antzelevitch C. A transient outward potassium current activator recapitulates the electrocardiographic manifestations of Brugada syndrome. Cardiovasc Res. 2009; 81:686-694. [PubMed: 19073629]

24. Yan GX, Antzelevitch C. Cellular basis for the Brugada syndrome and other mechanisms of arrhythmogenesis associated with ST segment elevation. Circulation. 1999; 100:1660-1666. [PubMed: 10517739]

25. Di Diego JM, Cordeiro JM, Goodrow RJ, Fish JM, Zygmunt AC, Peréz GJ, Scornik FS, Antzelevitch C. Ionic and cellular basis for the predominance of the Brugada syndrome phenotype in males. Circulation. 2002; 106:2004-2011. [PubMed: 12370227]

26. Antzelevitch C. Androgens and male predominance of the Brugada syndrome phenotype. PACE. 2003; 26:1429-1431. [PubMed: 12914617]

27. Johns JA, Anno T, Bennett PB, Snyders DJ, Hondeghem LM. Temperature and voltage dependence of sodium channel blocking and unblocking by O-demethyl encainide in isolated guinea pig myocytes. J Cardiovasc Pharmacol. 1989; 13:826-835. [PubMed: 2484076]

28. Akhtar M, Goldschlager NF. Brugada electrocardiographic pattern due to tricyclic antidepressant overdose. J Electrocardiol. 2006; 39:336-339. [PubMed: 16777522]

29. Chow BJ, Gollob M, Birnie D. Brugada syndrome precipitated by a tricyclic antidepressant. Heart. 2005; 91:651. [PubMed: 15831654]

30. Wang GK, Russell C, Wang SY. State-dependent block of voltage-gated Na+ channels by amitriptyline via the local anesthetic receptor and its implication for neuropathic pain. Pain. 2004; 110:166-174. [PubMed: 15275764]

31. Park KS, Kong ID, Park KC, Lee JW. Fluoxetine inhibits L-type Ca2+ and transient outward K+ currents in rat ventricular myocytes. Yonsei Med J. 1999; 40:144-151. [PubMed: 10333718]

32. Antzelevitch C, Yan GX. J wave syndromes. Heart Rhythm. 2010; 7:549-558. [PubMed: 20153265] 
33. Kapplinger JD, Tester DJ, Alders M, Benito B, Berthet M, Brugada J, Brugada P, Fressart V, Guerchicoff A, Harris-Kerr C, Kamakura S, Kyndt F, Koopmann TT, Miyamoto Y, Pfeiffer R, Pollevick GD, Probst V, Zumhagen S, Vatta M, Towbin JA, Shimizu W, Schulze-Bahr E, Antzelevitch C, Salisbury BA, Guicheney P, Wilde AA, Brugada R, Schott JJ, Ackerman MJ. An international compendium of mutations in the SCN5A-encoded cardiac sodium channel in patients referred for Brugada syndrome genetic testing. Heart Rhythm. 2010; 7:33-46. Epub 2009 Oct 8. [PubMed: 20129283]

34. Hu D, Barajas-Martinez H, Burashnikov E, Springer M, Wu Y, Varro A, Pfeiffer R, Koopmann TT, Cordeiro JM, Guerchicoff A, Pollevick GD, Antzelevitch C. A mutation in the beta 3 subunit of the cardiac sodium channel associated with Brugada ECG phenotype. Circ Cardiovasc Genet. 2009; 2:270-278. [PubMed: 20031595]

35. Vieweg WV, Wood MA. Tricyclic antidepressants, QT interval prolongation, and torsade de pointes. Psychosomatics. 2004; 45:371-377. [PubMed: 15345781]

36. Teschemacher AG, Seward EP, Hancox JC, Witchel HJ. Inhibition of the current of heterologously expressed HERG potassium channels by imipramine and amitriptyline. Br J Pharmacol. 1999; 128:479-485. [PubMed: 10510461]

37. Probst V, Wilde AA, Barc J, Sacher F, Babuty D, Mabo P, Mansourati J, Le SS, Kyndt F, Le CC, Guicheney P, Gouas L, Albuisson J, Meregalli PG, Le MH, Tan HL, Schott JJ. SCN5A mutations and the role of genetic background in the pathophysiology of Brugada syndrome. Circ Cardiovasc Genet. 2009; 2:552-557. [PubMed: 20031634]

38. Antzelevitch C, Fish JM. Therapy for the Brugada syndrome. Handb Exp Pharmacol. 2006:305330. [PubMed: 16610350]

39. Viskin S, Wilde AA, Tan HL, Antzelevitch C, Shimizu W, Belhassen B. Empiric quinidine therapy for asymptomatic Brugada syndrome: Time for a prospective registry. Heart Rhythm. 2009; 6:401-404. [PubMed: 19251219] 


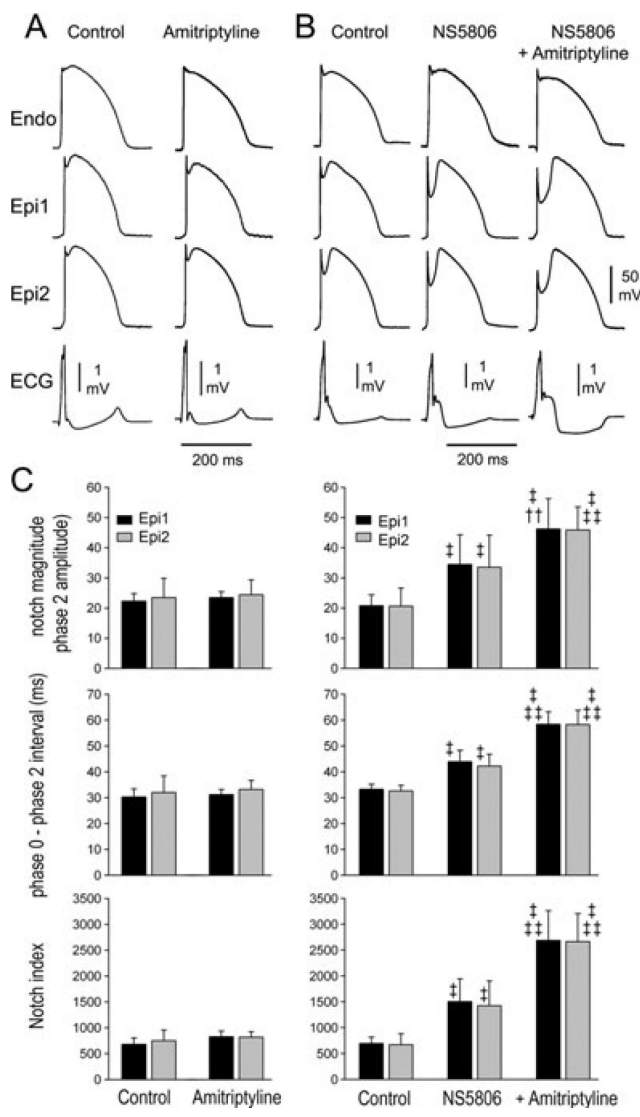

Figure 1.

Effect of amitriptyline on the electrophysiology of the coronary-perfused right ventricular wedge preparation in the absence and presence of the transient outward current agonist NS5806. The top panels show transmembrane action potentials simultaneously recorded from 2 epicardial (Epi) and one endocardial (Endo) site together with a pseudoelectrocardiogram (ECG). (A) Control and amitriptyline $(0.2 \mu \mathrm{M})$. (B) Control followed by NS5806 $(8 \mu \mathrm{M})$ and NS5806+amitriptyline $(0.2 \mu \mathrm{M})$. Basic cycle length $(\mathrm{BCL})=2,000 \mathrm{~ms}$; $\mathrm{n}=4$. (C) Bar graph showing the effect of amitriptyline alone or in combination with NS5086 on notch magnitude, Phase 0-phase 2 interval and notch index. BCL $=2,000 \mathrm{~ms}$; $\mathrm{n}$ $=9$. Values are mean $\pm \mathrm{SD} . \dagger \mathrm{P}<0.01$ vs control; $\ddagger \mathrm{P}<0.001$ vs control; $\ddagger \ddagger \mathrm{P}<0.001$ vs NS5806. 

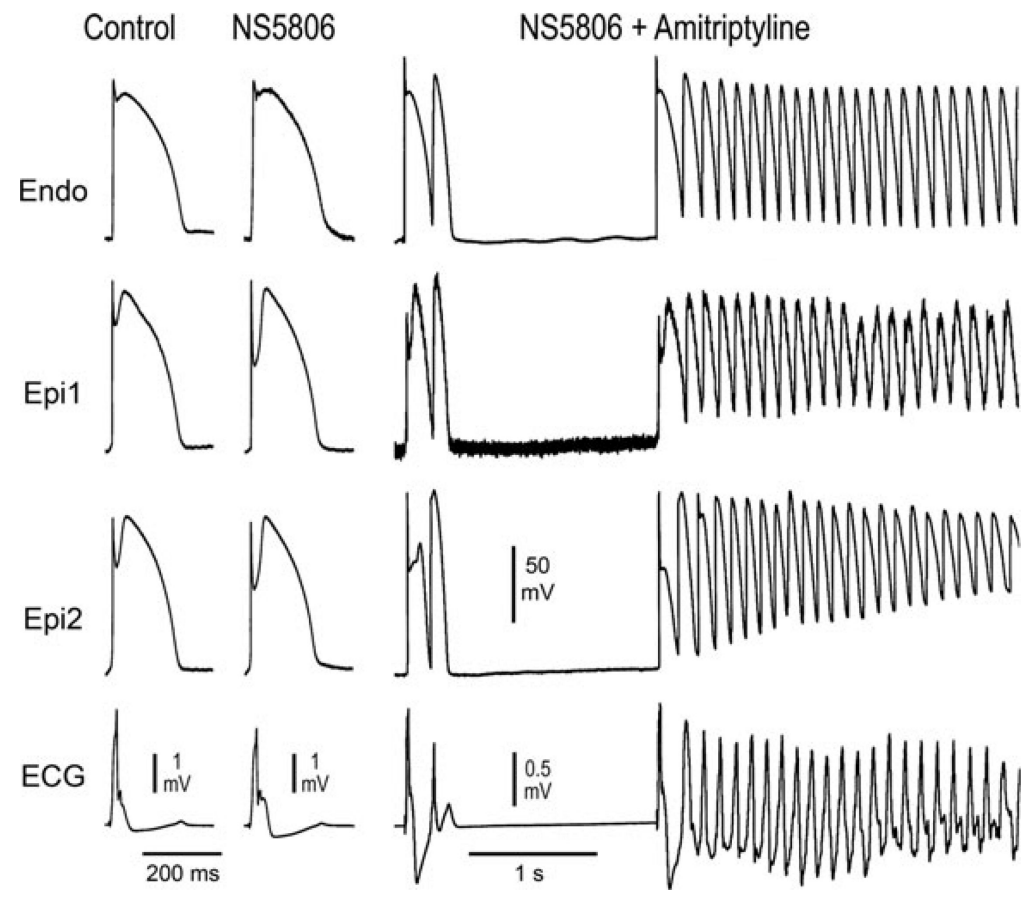

Figure 2.

Amitriptyline $(0.2 \mu \mathrm{M})$-induced Brugada phenotype in the presence of the transient outward potassium channel current (Ito) agonist NS5806. Each panel shows transmembrane action potentials (APs) simultaneously recorded from one endocardial (Endo) and 2 epicardial (Epi) sites together with a pseudo-electrocardiogram (ECG). NS5806 $(8 \mathrm{mM})$ accentuates the AP notch and $\mathrm{J}$ wave, but does not induce arrhythmic activity. Addition of amitriptyline $(0.2 \mu \mathrm{M})$ leads to the development of closelycoupled phase 2 reentrant extrasystoles. The phase 2 reentrant extrasystole with the briefer coupling interval precipitates polymorphic ventricular tachycardia. 

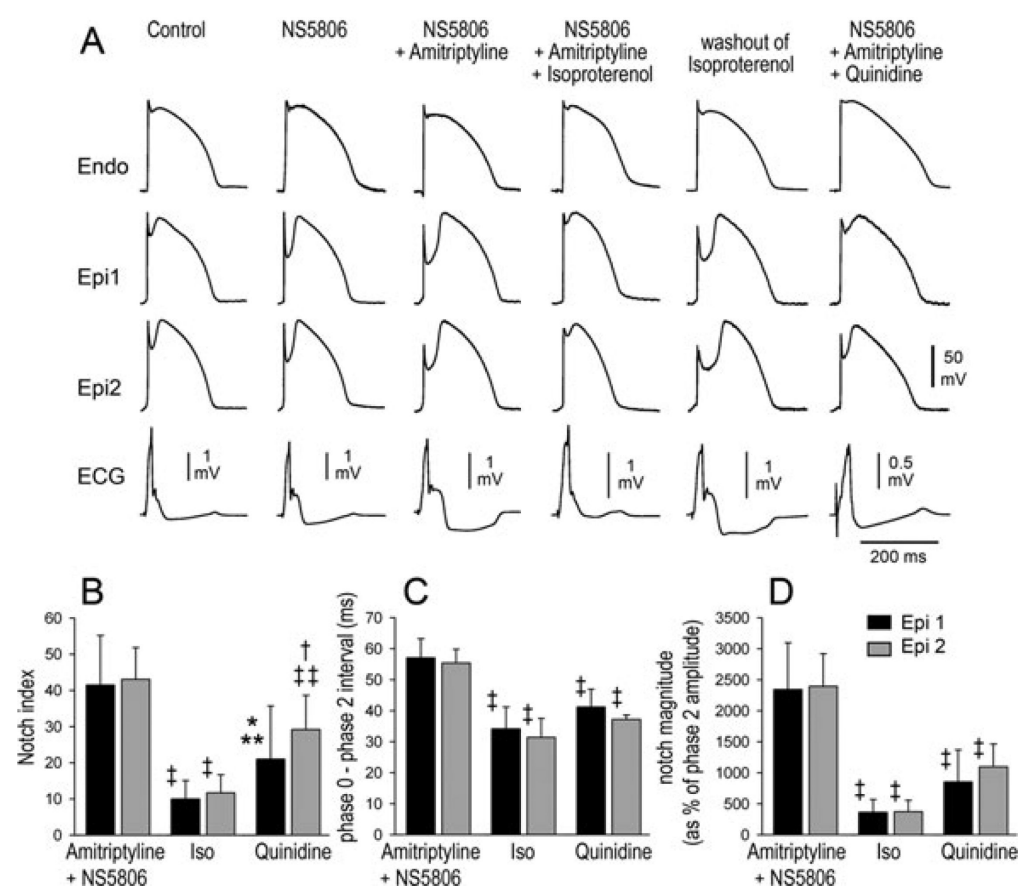

Figure 3.

Effect of isoproterenol $(100 \mathrm{nM})$ and quinidine $(10 \mathrm{mM})$ to antagonize amitriptyline $(0.2$ $\mu \mathrm{M}$ )-induced accentuation of the action potential notch and $\mathrm{J}$ wave in the presence of the transient outward potassium channel current agonist NS5806. (A) Each panel shows transmembrane action potentials simultaneously recorded from one endocardial (Endo) and 2 epicardial (Epi) sites. Basic cycle length $(B C L)=2,000 \mathrm{~ms}$. (B-D) Notch magnitude, Phase0-phase2 (Ph0-Ph2) interval and notch index are all significantly reduced following addition of isoproterenol (ISO) or quinidine to the coronary perfusate. $\mathrm{BCL}=2,000 \mathrm{~ms} ; \mathrm{n}=$ 4. Values are mean $\pm \mathrm{SD}$. $* \mathrm{P}<0.05$ vs amitriptyline; $\dagger \mathrm{P}<0.01$ vs amitriptyline; $\ddagger \mathrm{P}<0.001$ vs amitriptyline; $* * \mathrm{P}<0.05$ vs isoproterenol; $\ddagger \ddagger \mathrm{P}<0.001$ vs isoproterenol. 


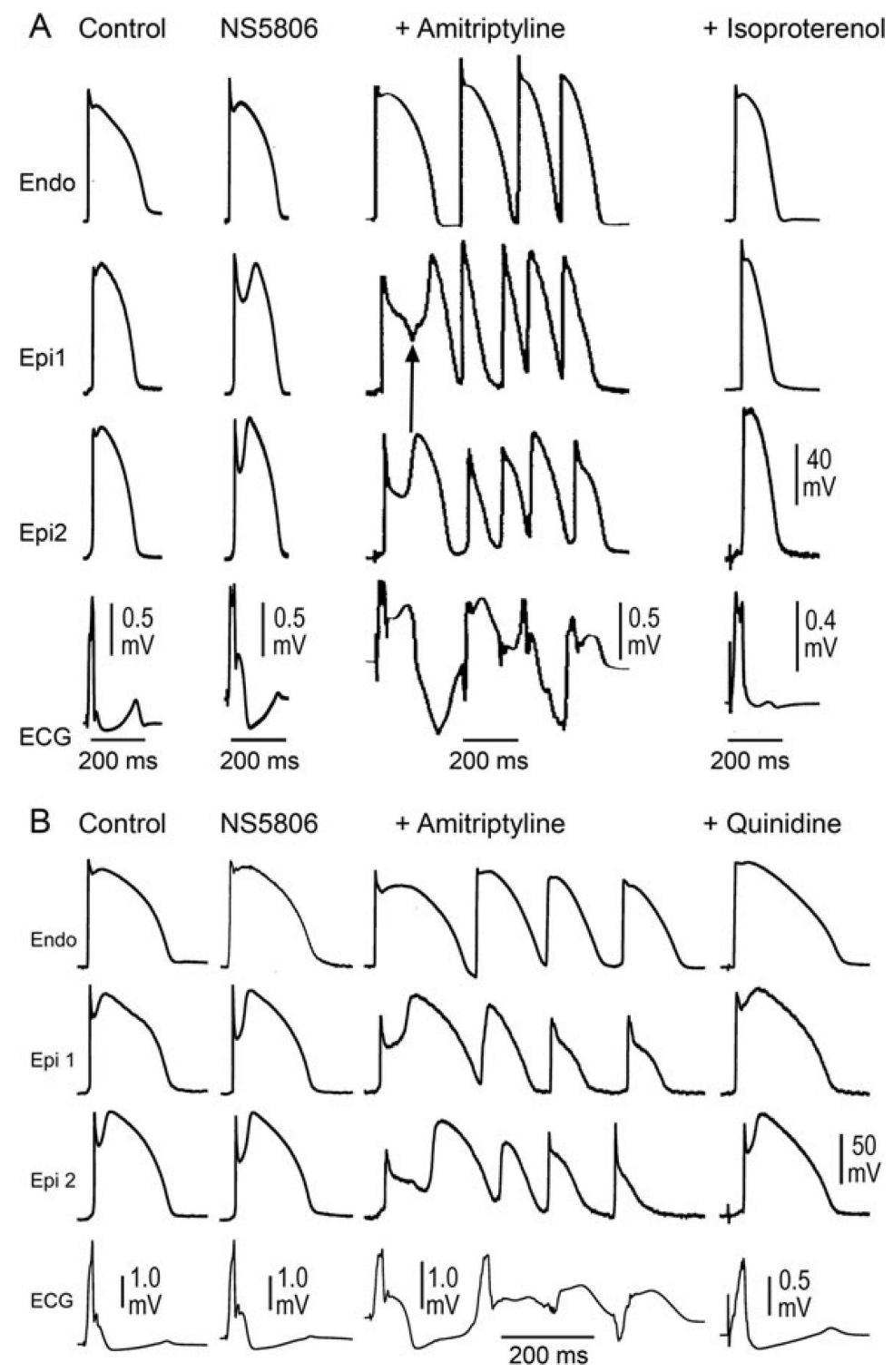

Figure 4.

Isoproterenol (ISO) and quinidine suppression of amitriptyline-induced Brugada syndrome phenotype. Shown are transmembrane action potentials (APs) simultaneously recorded from 2two sites on the epicardial (Epi) surface and one site on the endocardial (Endo) surface of a coronary-perfused right ventricular wedge preparation. The bottom trace in each panel is the pseudo-electrocardiogram (ECG) recorded across the bath. Both panels show traces recorded in control, after addition of the transient outward potassium channel current agonist NS5806 $(8 \mathrm{mM})$ to the coronary perfusate, and after further addition of amitriptyline $(0.2$ $\mu \mathrm{M})$. Amitriptyline further accentuates the AP notch and $\mathrm{J}$ wave, leading to loss of the AP dome at one Epi site but not the other. Heterogeneous loss of the dome leads to the development of a closelycoupled phase 2 reentrant extrasystole which precipitates a polymorphic ventricular tachycardia. (A) Addition of isoproterenol $(100 \mathrm{nM})$ restores the AP dome, thus restoring homogeneity and aborting all arrhythmic activity. (B) Addition of quinidine $(10 \mathrm{mM})$ restores the AP dome, thus restoring homogeneity and suppressing all arrhythmic activity. 

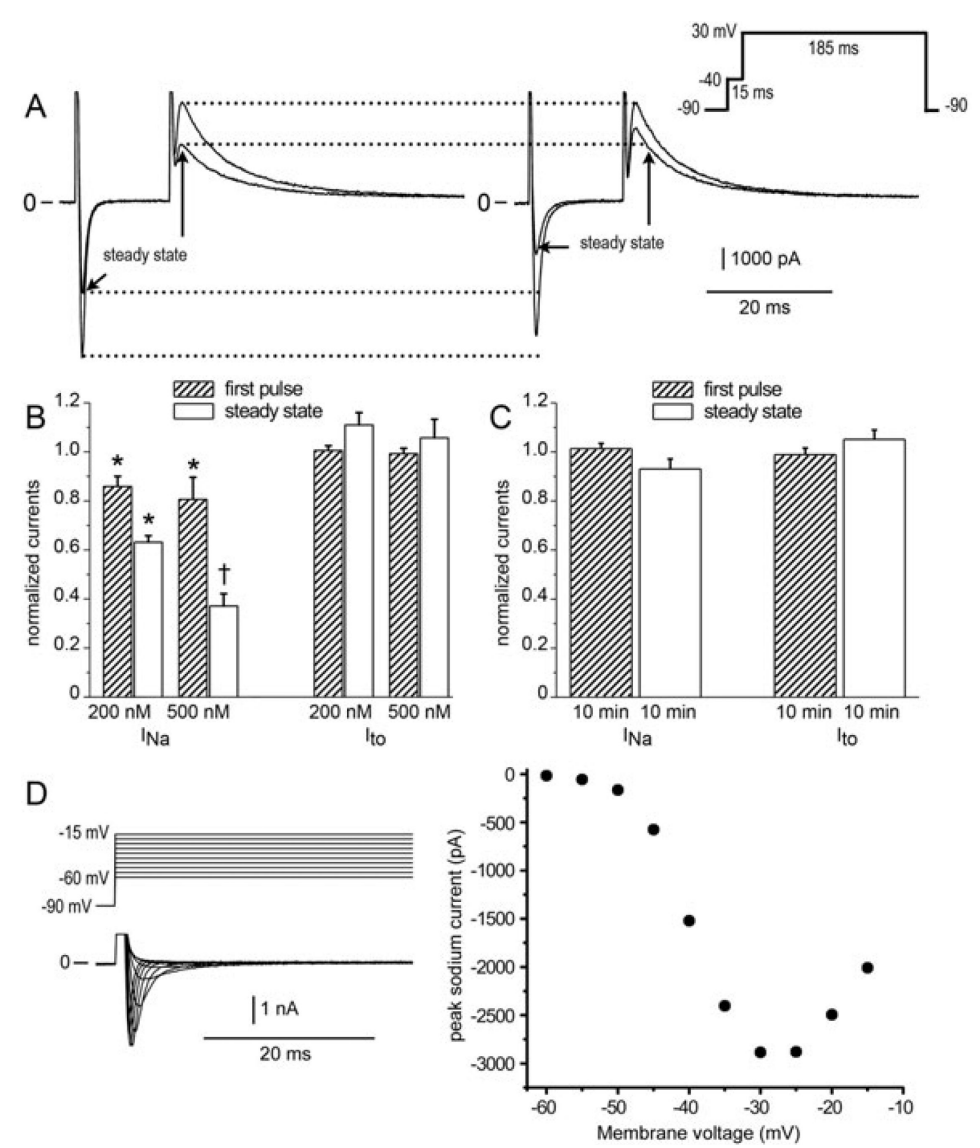

Figure 5.

Amitriptyline-induced use-dependent block and concentration-dependent block of fast sodium current $\left(\mathrm{I}_{\mathrm{Na}}\right)$ but not transient outward potassium channel current $\left(\mathrm{I}_{\mathrm{to}}\right)$. (A) Simultaneous measurements of fast $\mathrm{I}_{\mathrm{Na}}$ and $\mathrm{I}_{\mathrm{to}}$ during the first pulse and 40th pulse (steady state) in control solution (left panel) and 6 min after addition of $0.2 \mu \mathrm{M}$ amitriptyline (right panel). (B) Bar graph of $\mathrm{I}_{\mathrm{Na}}$ and $\mathrm{I}_{\mathrm{to}}$ of the first pulse and 40th pulse (steady state) in the presence of $0.2 \mu \mathrm{M}$ and $0.5 \mu \mathrm{M}$ amitriptyline normalized to control values (average \pm SEM, $\mathrm{n}=6$ ). (C) Time controls in the absence of drug. Pulse trains were elicited repeatedly over a time course of $10 \mathrm{~min}$. First pulse and steady state currents during the last train of the $10 \mathrm{~min}$ period were measured as a fraction of the currents during the first train (average \pm SEM, $n=$ 6). (D) Current-voltage relation showing voltage control during activation of sodium channels at $37^{\circ} \mathrm{C}$ in reduced external sodium. $\mathrm{I}_{\mathrm{Na}}$ was recorded in potassium-free solution containing $40 \mathrm{mM} \mathrm{NaCl}$ and $0.3 \mathrm{mM} \mathrm{CdCl}_{2}$. Top, voltage template. Middle, currents recorded in drug-free solution. Bottom, the current-voltage relation shown for the traces above. 

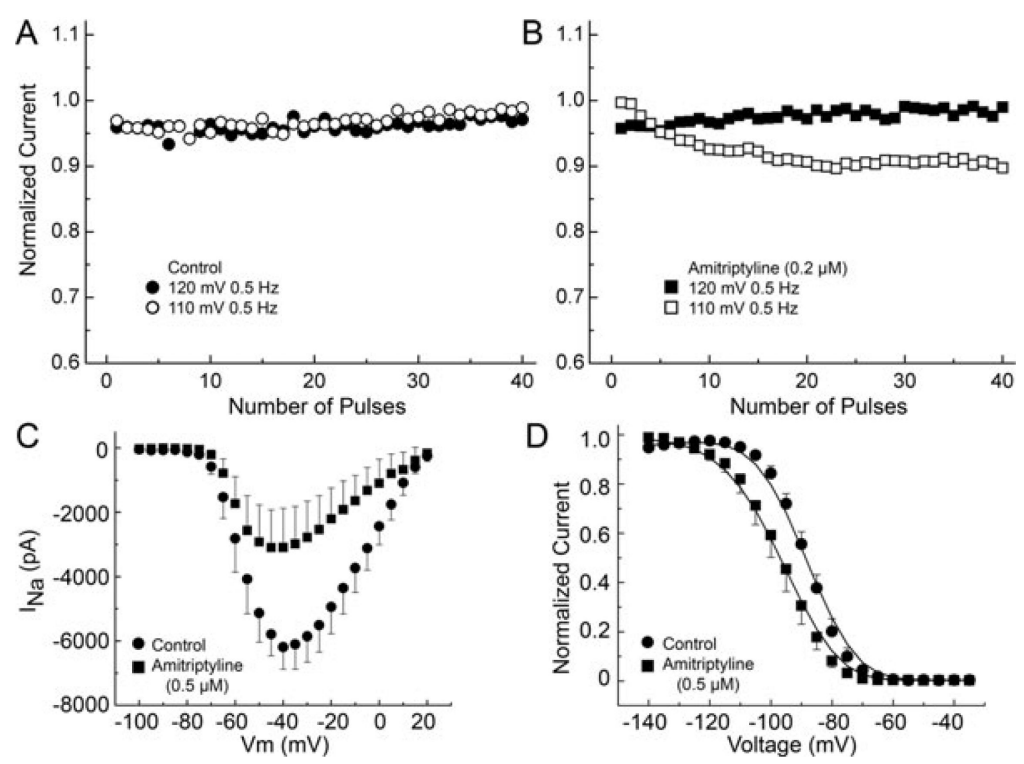

Figure 6.

Voltage-dependent effects of amitriptyline on sodium channel activity in TSA201 cells transfected with SCN5A and SCN1B. Use-dependent block (UDB) was examined at $0.5 \mathrm{~Hz}$ with $20 \mathrm{~ms}$-long test pulse to $40 \mathrm{mV}$ from a holding potential (HP) of $-110 \mathrm{mV}$ and -120 $\mathrm{mV}$ before and after amitriptyline. (A) Control recordings. (B) Amitriptyline $(0.2 \mu \mathrm{M})$ causes UDB at HP $-110 \mathrm{mV}$. INa recordings were elicited by $200-\mathrm{ms}-$ pulses at $0.5 \mathrm{~Hz}$ in $\mathrm{HP} 120 \mathrm{mV}$ and $-110 \mathrm{mV}$. (C) Amitriptyline reduces maximum current at $20 \mathrm{mV}(\mathrm{P}<$ 0.01). (D) Steady-state inactivation curve; amitriptyline shifts the half-inactivation potential (Hinf50) $(-91.6 \pm 0.5 \mathrm{vs}-98.3 \pm 0.3, \mathrm{P}<0.01)$ and changes the slope factor $(6.3 \pm 0.05 \mathrm{vs}$ $7.3 \pm 0.39, \mathrm{P}<0.05)$. 


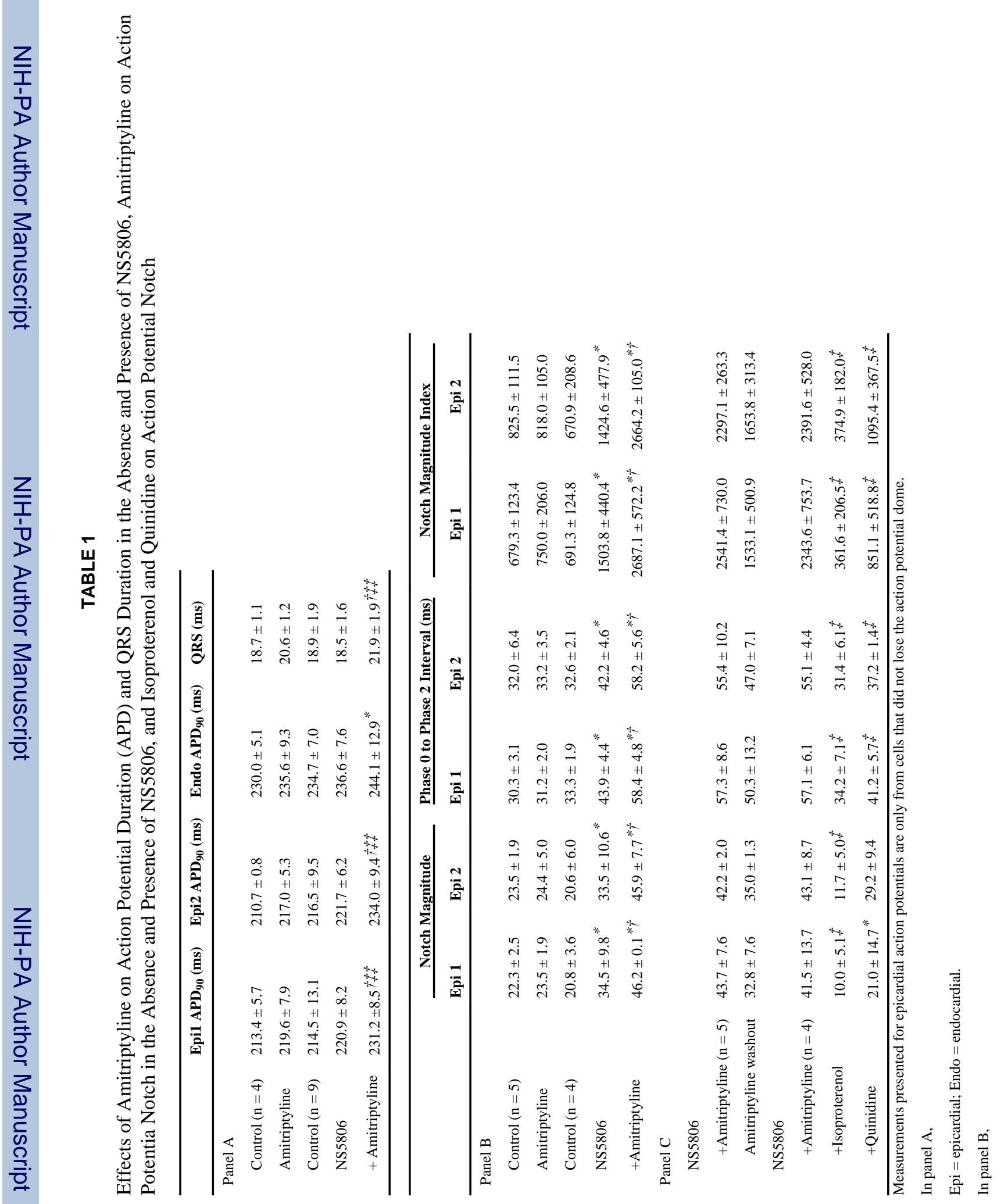




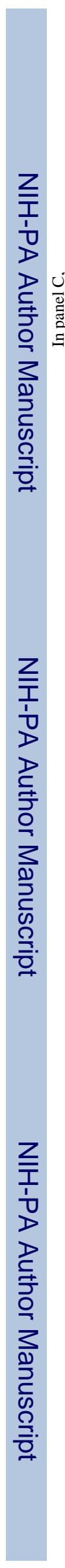

MINOURA et al.

Page 19

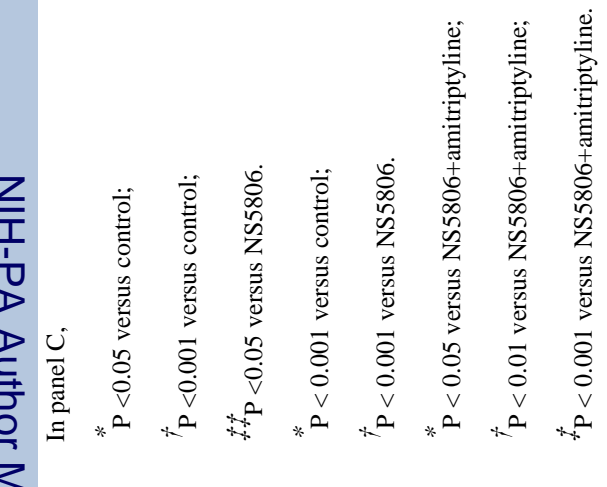

